\title{
A Fuzzy MCDM Approach for Green Supplier Selection from the Economic and Environmental Aspects
}

\author{
Hsiu Mei Wang Chen, ${ }^{1}$ Shuo-Yan Chou, ${ }^{1}$ Quoc Dat Luu, ${ }^{2}$ and Tiffany Hui-Kuang Yu ${ }^{3}$ \\ ${ }^{1}$ Department of Industrial Management, National Taiwan University of Science and Technology, No. 43, Section 4, \\ Keelung Road, Da'an District, Taipei 10607, Taiwan \\ ${ }^{2}$ University of Economics and Business, Vietnam National University, 144 Xuan Thuy, Hanoi, Vietnam \\ ${ }^{3}$ Department of Public Finance, Feng Chia University, Taichung, Taiwan
}

Correspondence should be addressed to Hsiu Mei Wang Chen; gracesmc1@gmail.com

Received 22 October 2015; Revised 26 January 2016; Accepted 31 January 2016

Academic Editor: Young Hae Lee

Copyright (C) 2016 Hsiu Mei Wang Chen et al. This is an open access article distributed under the Creative Commons Attribution License, which permits unrestricted use, distribution, and reproduction in any medium, provided the original work is properly cited.

\begin{abstract}
Due to the challenge of rising public awareness of environmental issues and governmental regulations, green supply chain management (SCM) has become an important issue for companies to gain environmental sustainability. Supplier selection is one of the key operational tasks necessary to construct a green SCM. To select the most suitable suppliers, many economic and environmental criteria must be considered in the decision process. Although numerous studies have used economic criteria such as cost, quality, and lead time in the supplier selection process, only some studies have taken into account the environmental issues. This study proposes a comprehensive fuzzy multicriteria decision making (MCDM) approach for green supplier selection and evaluation, using both economic and environmental criteria. In the proposed approach, a fuzzy analytic hierarchy process (AHP) is employed to determine the important weights of criteria under vague environment. In addition, a fuzzy technique for order performance by similarity to ideal solution (TOPSIS) is used to evaluate and rank the potential suppliers. Finally, a case study in Luminance Enhancement Film (LEF) industry is presented to illustrate the applicability and efficiency of the proposed method.
\end{abstract}

\section{Introduction}

The change of climate and the escalation in global warming have driven increasing worldwide concern about the environmental protection. To gain and retain competitive advantages in the global market, firms have started to focus on the development of green products to satisfy customer environmental needs and requirements [1]. Consequently, green supply chain management (SCM) development with environmental thinking and strategies has become an important task for firms [2].

Green supplier selection is a critical activity because the environmental performance of the supply chain is affected significantly by its constituent supplier [3, 4]. Environmental and economic dimensions must be considered simultaneously when firms select a suitable supplier [5]. The green suppliers are chosen and must fit a firm's expectations and objectives, so as to minimize negative environmental impact and maximize economic performance. Thus, the green supplier selection process integrates environmental concerns into the interorganizational practices of SCM including reverse logistics [6].

Despite the growing work of green SCM, however, existent researches generally concentrate mainly on decision making techniques with complicated mathematical computational models in supplier selection problem. In addition, consider environmental aspects in isolated way [7]. The implementation of green supply management is not well understood, and understanding the environmental sustainability practices involving SCM activities is still limited [8]. Therefore, more researches are needed to answer how companies actually carry out green supplier selection [9] considering environmental and economic aspects simultaneously.

In recent years, TOPSIS (technique for order performance by similarity to ideal solution), proposed by Shih et al. [10], has been a popular technique to solve MCDM problems. 
The fundamental idea of TOPSIS is that the chosen alternative should have the shortest Euclidian distance from the positiveideal solution and the farthest distance from the negativeideal solution. The positive-ideal solution is a solution that maximizes the benefit criteria and minimizes the cost criteria, whereas the negative ideal solution maximizes the cost criteria and minimizes the benefit criteria. In the classical TOPSIS method, the weights of the criteria and the ratings of alternatives are known precisely, and crisp values are used in the evaluation process. Under many circumstances, however, crisp data are inadequate to simulate real-life decision problems. Consequently, a fuzzy TOPSIS method is proposed to deal with the deficiency in the traditional TOPSIS. The method based on the weights of criteria and ratings of alternatives are evaluated by linguistic variables represented by fuzzy numbers. Some advantages of the TOPSIS [11] and fuzzy TOPSIS method include the following: (i) a sound logic that embodies rational human choice; (ii) a simple computation process that can be used and programmed easily; (iii) the number of steps that remains the same regardless of the number of attributes; (iv) a scalar value that accounts for both the best and worst alternatives at the same time. As a result, fuzzy TOPSIS approach has been broadly applied to decisionmaking applications over the past few decades.

Several studies in the literature have mentioned the difficulty of weighting the criteria and keeping consistency of judgment when using fuzzy TOPSIS. Thus, the combination of the fuzzy TOPSIS with another method, such as fuzzy analytic hierarchy process (AHP), might be able to determine proper objective weightings under a vague environment. The AHP, a powerful tool in applying MCDA, was introduced and developed by Büyüközkan and Çifçi [12]. The AHP helps identify the weights or priority vector of the alternatives or the criteria, using a hierarchical model that includes target, main criteria, subcriteria, and alternatives. Nevertheless, a major disadvantage of AHP is that it is unable to handle adequately the inherent uncertainty and imprecision of human thinking. Fuzzy AHP has been developed to solve this problem [13]. In FAHP method, the application of the fuzzy comparison ratio tolerates vagueness in the model. Decision makers use natural linguistic emphasis as well as certain numbers to evaluate criteria and alternatives. Fuzzy AHP impressively resembles human thought and perception. In the literature, many studies have used either fuzzy TOPSIS or fuzzy AHP methods to select and evaluate the suppliers [14-19]. However, few studies have proposed an integrated fuzzy MCDM approach for suppliers selection and evaluation, especially in the case of green suppliers.

This paper proposes an integrated fuzzy multicriteria decision making (MCDM) approach, to solve problems of green supplier selection and supply chain construction simultaneously, effectively, and efficiently. To address the research need, we leverage a small and medium sized high tech company to draw a case study of an actual green supplier selection and green SCM experience of a Taiwanese optical prism manufacturing entity (hereinafter referred to as TOP, a pseudonym), in the Luminance Enhancement Film (LEF) industry. The company was selected because the rapidly changing environment of the optical prism industry forces firm to develop ongoing sustainable capabilities and to respond to the uncertain environment.

The remainder of this paper is organized as follows. In Section 2 green supplier selection criteria and method literature is reviewed. The basic concepts of fuzzy numbers are shown in Section 3. The integrated fuzzy MCDM approach is proposed in Section 4. Section 5 applies the proposed approach to a real case. Concluding remarks are presented in Section 6.

\section{Literature Review on Green Supplier Selection Criteria and Methods}

As a result of escalated global warming and increasing environmental protection awareness, EU environmental orders such as RoHS, WEEE, ErP, and REACH have been enforced. The supply chains of firm and the products are required to become more ecofriendly, especially in the electronics industry. The circumstance has driven supply chains not only to comply with environmental policies but also to enforce firms govern their own corporate environmental policies to sustain in the global market.

Green SCM has become a strategy to improve a firm's environmental and economic performance $[25,38]$. Procurement constitutes one of the key strategic functions in SCM. Selecting the right supplier gives the firm a competitive edge to either reduce costs, enhance the quality [39], or minimize negative environmental impact, avoiding violating relevant legislation [20].

In practice, when a firm is purchasing, the professional purchaser chooses the favorite suppliers on the basis of specifications and conditions. A firm primarily prioritizes economic criteria such as cost, quality, delivery, and flexibility. The environmental certificate of ISO 14000, as one of environmental criteria, is usually applied for purchaser reference only. Efficient evaluation criteria can help the firm to reduce the risks associated with suppliers [21]. Current literatures address the most popular economic criteria considered by the decision makers for supplier selection and evaluation which are quality $[4,12,22,23,25]$, cost [20-24], delivery [21, 23, 26, 27], flexibility [22, 28, 29], and relationship [23, 28, 29]. Environmental criteria are environmental management system $[2,19,28,32-34,36,37]$, green competencies [2, 33, 34, 36, 37], and ecodesign [28, 32, 34, 35]. Few studies simultaneously considered economic and environmental aspects for green supplier selection.

Currently, environmental factors play a vital role for the long term success of a supply chain, and the purchasing process has become more complicated with environmental consideration [3]. Several studies have examined the criteria of supplier selection and focused on different approaches or criteria. Table 1 presents the most commonly used criteria in the literature to evaluate the environmental and economic performance of green supplier selection.

In the literature, numerous techniques have been developed to select the most suitable suppliers or green suppliers based on specific methods including fuzzy AHP [3, 40-43], analytic network process (ANP) $[6,29]$, data envelopment analysis (DEA) [6], MCDM approach [13, 21, 31, 33, 44-47], 
TABLE 1: Green supplier selection and evaluation criteria.

\begin{tabular}{|c|c|c|c|}
\hline Criteria & Subcriteria & Sub-subcriteria/definition & References \\
\hline \multirow{9}{*}{ Economic criteria } & Cost & Product price, logistics cost, and payment terms & {$[20-24]$} \\
\hline & Quality & $\begin{array}{l}\text { ISO quality system installed, quality award, product performance, } \\
\text { warranties and claim policies, and repair and return rate }\end{array}$ & {$[4,12,22,23,25]$} \\
\hline & Delivery & $\begin{array}{l}\text { Lead time, on-time delivery, safety and security of components, and } \\
\text { appropriateness of the packaging }\end{array}$ & {$[21,23,26,27]$} \\
\hline & Technology & $\begin{array}{l}\text { Communication and e-commerce systems, capability of research } \\
\text { development and innovation, and production facilities and capacity }\end{array}$ & {$[22,23,26]$} \\
\hline & Flexibility & $\begin{array}{l}\text { Product volume changes, short setup time, conflict resolution, using } \\
\text { flexible machines, the demand that can be profitably sustained, and } \\
\text { time or cost required to add new products to the existing production } \\
\text { operation }\end{array}$ & {$[22,28,29]$} \\
\hline & $\begin{array}{l}\text { Financial } \\
\text { capability }\end{array}$ & Financial position, economical stability, and price strategy & {$[12,23,30]$} \\
\hline & Culture & Communication openness, vendor's image, and mutual trust & {$[20,23,27]$} \\
\hline & Innovativeness & New launch of products and new launch of technologies & [31] \\
\hline & Relationship & $\begin{array}{l}\text { Long term relationship, relationship closeness, communication } \\
\text { openness, and reputation for integrity }\end{array}$ & {$[23,28,29]$} \\
\hline \multirow{11}{*}{ Environmental criteria } & $\begin{array}{l}\text { Pollution } \\
\text { production }\end{array}$ & $\begin{array}{l}\text { Average volume of air pollutants, waste water, solid waste, and } \\
\text { harmful materials released }\end{array}$ & {$[19,22,32]$} \\
\hline & $\begin{array}{l}\text { Pollution } \\
\text { control }\end{array}$ & Remediation and end-of-pipe controls & {$[2,19,33]$} \\
\hline & $\begin{array}{l}\text { Resource } \\
\text { consumption }\end{array}$ & Consumption of resources in terms of raw material, energy, and water & {$[19,32]$} \\
\hline & Ecodesign & $\begin{array}{l}\text { Design for resource efficiency, design of products for reuse, recycle, } \\
\text { and recovery of material, design for reduction, or elimination of } \\
\text { hazardous materials }\end{array}$ & {$[28,32,34,35]$} \\
\hline & $\begin{array}{l}\text { Environmental } \\
\text { management } \\
\text { system }\end{array}$ & $\begin{array}{l}\text { Environmental certificates such as ISO } 14000 \text {, continuous monitoring } \\
\text { and regulatory compliance, environmental policies, green process } \\
\text { planning, and internal control process }\end{array}$ & {$[2,19,28,32-34,36,37]$} \\
\hline & Green image & Ratio of green customers to total customers and social responsibility & {$[2,33,35]$} \\
\hline & $\begin{array}{l}\text { Green } \\
\text { competencies }\end{array}$ & $\begin{array}{l}\text { Materials used in the supplied components that reduce the impact on } \\
\text { natural resources and ability to alter process and product for reducing } \\
\text { the impact on natural resources }\end{array}$ & {$[2,33,34,36,37]$} \\
\hline & Green product & $\begin{array}{l}\text { Use of recycled and nontoxic materials, green packaging, and excess } \\
\text { packaging reduction }\end{array}$ & {$[6,34,36]$} \\
\hline & $\begin{array}{l}\text { Staff } \\
\text { environmental } \\
\text { training }\end{array}$ & Staff training on environmental issues & [36] \\
\hline & $\begin{array}{l}\text { Management } \\
\text { commitment }\end{array}$ & $\begin{array}{l}\text { Commitment of senior managers to support and improve green } \\
\text { supply chain management initiatives }\end{array}$ & {$[34,36]$} \\
\hline & $\begin{array}{l}\text { Green } \\
\text { Technology }\end{array}$ & $\begin{array}{l}\text { The application of the environmental science to conserve the natural } \\
\text { environment and resources and to curb the negative impact of human } \\
\text { involvement }\end{array}$ & {$[6,34]$} \\
\hline
\end{tabular}

structural equation modeling and fuzzy logic [23], optimum mathematical planning model [35], linguistic preferences [28], fuzzy linguistic computing approach [27], Fuzzy Adaptive Resonance Theory algorithm [30], and genetic algorithm (GA) [48].

Although a number of methods have been studied, most of the studies have only used either economic or environmental criteria for evaluating the suppliers. There are few studies considering economic and environmental criteria simultaneously in the supplier selection process.
And each of those methods has its own advantages and disadvantages; this study proposes the integrated approach by combining the two most popular techniques for solving green supplier problems, that is, fuzzy TOPSIS and fuzzy AHP. In the proposed approach, the fuzzy AHP is employed to determine the important weights of criteria under vague environment. Then, the fuzzy TOPSIS is used to evaluate and rank the potential suppliers. In addition, both economic and environmental criteria are considered in proposed MCDM approach. 


\section{Fuzzy Numbers}

There are various ways to define fuzzy numbers. This paper defines the concept of fuzzy numbers as follows $[49,50]$.

Definition 1. A real fuzzy number $A$ is described as any fuzzy subset of the real line $R$ with membership function $f_{A}$, which has the following properties:

(a) $f_{A}$ is a continuous mapping from $R$ to the closed interval $[0,1]$.

(b) $f_{A}(x)=0$, for all $x \in(-\infty, a]$.

(c) $f_{A}$ is strictly increasing on $[a, b]$.

(d) $f_{A}(x)=1$, for all $x \in[b, c]$;

(e) $f_{A}$ is strictly decreasing on $[c, d]$.

(f) $f_{A}(x)=0$, for all $x \in(d, \infty]$,

where $a, b, c$, and $d$ are real numbers. Unless elsewhere specified, this research assumes that $A$ is convex and bounded (i.e., $-\infty<a, d<\infty$ ).

Definition 2. The fuzzy number $A=[a, b, c, d]$ is a trapezoidal fuzzy number if its membership function is given by

$$
f_{A}(x)= \begin{cases}f_{A}^{L}(x), & a \leq x \leq b \\ 1, & b \leq x \leq c \\ f_{A}^{R}(x), & c \leq x \leq d \\ 0, & \text { otherwise }\end{cases}
$$

where $f_{A}^{L}(x)$ and $f_{A}^{R}(x)$ are the left and right membership functions of $A$, respectively [50].

When $b=c$, the trapezoidal fuzzy number is reduced to a triangular fuzzy number and can be denoted by $A=$ $(a, b, d)$. Thus, triangular fuzzy numbers are special cases of trapezoidal fuzzy numbers.

Definition 3 (the distance between fuzzy triangular numbers). Let $A=\left(a_{1}, b_{1}, d_{1}\right)$ and $B=\left(a_{2}, b_{2}, d_{2}\right)$ be two triangular fuzzy numbers. The distance between them is given using the vertex method by

$$
d(A, B)=\sqrt{\frac{1}{3}\left[\left(a_{1}-a_{2}\right)^{2}+\left(b_{1}-b_{2}\right)^{2}+\left(d_{1}-d_{2}\right)^{2}\right]} .
$$

Definition 4 ( $\alpha$-cuts). The $\alpha$-cuts of fuzzy number $A$ can be defined as $A^{\alpha}=\left\{x \mid f_{A}(x) \geq \alpha\right\}, \alpha \in[0,1]$, where $A^{\alpha}$ is a nonempty bounded closed interval contained in $R$ and can be denoted by $A^{\alpha}=\left[A_{l}^{\alpha}, A_{u}^{\alpha}\right]$, where $A_{l}^{\alpha}$ and $A_{u}^{\alpha}$ are its lower and upper bounds, respectively [50]. For example, if a triangular fuzzy number $A=(a, b, d)$, then the $\alpha$-cuts of $A$ can be expressed as follows:

$$
A^{\alpha}=\left[A_{l}^{\alpha}, A_{u}^{\alpha}\right]=[(b-a) \alpha+a,(b-d) \alpha+d] .
$$

Definition 5 (arithmetic operations on fuzzy numbers). Given fuzzy numbers $A$ and $B$, where $A, B \in R^{+}$, the $\alpha$-cuts of $A$ and $B$ are $A^{\alpha}=\left[A_{l}^{\alpha}, A_{u}^{\alpha}\right]$ and $B^{\alpha}=\left[B_{l}^{\alpha}, B_{u}^{\alpha}\right]$, respectively.
By the interval arithmetic, some main operations of $A$ and $B$ can be expressed as follows [50]:

$$
\begin{aligned}
& (A \oplus B)^{\alpha}=\left[A_{l}^{\alpha}+B_{l}^{\alpha}, A_{u}^{\alpha}+B_{u}^{\alpha}\right], \\
& (A \ominus B)^{\alpha}=\left[A_{l}^{\alpha}-B_{u}^{\alpha}, A_{u}^{\alpha}-B_{l}^{\alpha}\right], \\
& (A \otimes B)^{\alpha}=\left[A_{l}^{\alpha} \cdot B_{l}^{\alpha}, A_{u}^{\alpha} \cdot B_{u}^{\alpha}\right], \\
& (A \oslash B)^{\alpha}=\left[\frac{A_{l}^{\alpha}}{B_{u}^{\alpha}}, \frac{A_{u}^{\alpha}}{B_{l}^{\alpha}}\right], \\
& (A \otimes r)^{\alpha}=\left[A_{l}^{\alpha} \cdot r, A_{u}^{\alpha} \cdot r\right], \quad r \in R^{+} .
\end{aligned}
$$

\section{Proposed Approach for Green Suppliers Selection}

In this section, an approach for green supplier selection by combining fuzzy TOPSIS and fuzzy AHP method is presented. The proposed approach offers a new way to solve the green supplier selection problem effectively and efficiently, since it enables decision makers to minimize the negative environmental impact of the supply chain while simultaneously maximizing business performance. The procedure of the proposed approach is stated as follows.

Step 1. Identify a number of economic and environmental criteria.

Step 2. Aggregate the important weights of the criteria.

Step 3. Aggregate the ratings of suppliers versus the criteria.

Step 4. Normalize the fuzzy decision matrix.

Step 5. Construct the weighted normalized fuzzy decision matrix.

Step 6. Calculate normalized weighted rating.

Step 7. Calculate $A^{+}, A^{-}, d_{i}^{+}$, and $d_{i}^{-}$.

Step 8. Obtain the closeness coefficient.

Assume that a committee of $l$ decision makers $\left(D_{t}, t=1 \sim\right.$ $l)$ is responsible for evaluating $m$ suppliers $\left(A_{i}, i=1 \sim m\right)$ under $n$ selected criteria $\left(C_{j}, j=1 \sim n\right)$, where the suitability ratings of alternatives under each of the criteria, as well as the weights of the criteria, are assessed in linguistic terms [51, 52] represented by triangular fuzzy numbers.

4.1. Identify a Number of Economic and Environmental Criteria. In this study, the criteria are classified into two categories, that is, economic criteria $\left(C_{j}, j=1, \ldots, l\right)$ and environmental criteria $\left(C_{j}, j=l+1, \ldots, n\right)$. The number of economic and environmental criteria is selected from Table 1 through screening by the decision makers.

4.2. Aggregate the Important Weights of the Criteria. In this section, a fuzzy AHP is applied to obtain more decisive judgments by prioritizing the economic and environmental 
criteria. Several fuzzy AHP methods have been proposed in literature to solve the MCDM problems. This study adopts the extent analysis method proposed by Chang [53] due to its popularity and computational simplicity. Chang's [53] method is briefly discussed as follows.

Let $X=\left\{x_{1}, x_{2}, \ldots, x_{n}\right\}$ be an object set and let $U=$ $\left\{u_{1}, u_{2}, \ldots, u_{m}\right\}$ be a goal set. According to Chang [53], each object is taken and an extent analysis for each goal $\left(g_{i}\right)$ is performed, respectively. Therefore, the $m$ extent analysis values for each object are obtained as $M_{g_{i}}^{1}, M_{g_{i}}^{2}, \ldots, M_{g_{i}}^{n}, i=$ $1,2, \ldots, n$, where $M_{g_{i}}^{j}(j=1,2, \ldots, m)$ are triangular fuzzy numbers (TFNs).

Assume that $M_{g_{i}}^{j}$ are the values of extent analysis of the $i$ th object for $m$ goals. The value of fuzzy synthetic extent $S_{i}$ is defined as follows:

$$
S_{i}=\sum_{j=1}^{m} M_{g_{i}}^{j} \otimes\left[\sum_{i=1}^{n} \sum_{j=1}^{m} M_{g_{i}}^{j}\right]^{-1},
$$

where $\sum_{j=1}^{m} M_{g_{i}}^{j}=\left(\sum_{j=1}^{m} l_{j}, \sum_{j=1}^{m} m_{j}, \sum_{j=1}^{m} u_{j}\right), j=1,2$, $\ldots, m, i=1,2, \ldots, n$.

Let $M_{1}=\left(l_{1}, m_{1}, u_{1}\right)$ and $M_{2}=\left(l_{2}, m_{2}, u_{2}\right)$ be two TFNs, whereby the degree of possibility of $M_{1} \geq M_{2}$ is defined as follows:

$$
V\left(M_{1} \geq M_{2}\right)=\sup _{x \geq y}\left[\min \left(\mu_{M_{1}}(x), \mu_{M_{2}}(x)\right)\right] .
$$

The membership degree of possibility is expressed as follows:

$$
\begin{aligned}
& V\left(M_{1} \geq M_{2}\right)=\operatorname{hgt}\left(M_{1} \cap M_{2}\right)=\mu_{M_{2}}(d) \\
& = \begin{cases}1 & \text { if } m_{1} \geq m_{2} \\
0 & \text { if } l_{2} \geq u_{1} \\
\frac{l_{2}-u_{1}}{\left(l_{2}-u_{1}\right)+\left(m_{1}-m_{2}\right)} & \text { otherwise, }\end{cases}
\end{aligned}
$$

where $d$ is the ordinate of the highest intersection point of two membership functions $\mu_{M_{1}}(x)$ and $\mu_{M_{2}}(x)$.

The degree of possibility for a convex fuzzy number to be greater than $k$ convex fuzzy numbers is defined as follows:

$$
\begin{aligned}
V\left(M \geq M_{1}, M_{2}, \ldots, M_{k}\right)=\min V(M \geq & \left.M_{i}\right), \\
& i=1,2, \ldots, k .
\end{aligned}
$$

The weight vector is given by

$$
W^{\prime}=\left(d^{\prime}\left(A_{1}\right), d^{\prime}\left(A_{2}\right), \ldots, d^{\prime}\left(A_{n}\right)\right)^{T},
$$

where

$$
\begin{aligned}
d^{\prime}\left(A_{i}\right)=\min & V\left(S_{i} \geq S_{k}\right), \\
& (i=1,2, \ldots, n), k=1,2, \ldots, n ; k \neq i .
\end{aligned}
$$

Via normalization, we obtain the weight vectors as follows:

$$
W=\left(d\left(A_{1}\right), d\left(A_{2}\right), \ldots, d\left(A_{n}\right)\right)^{T},
$$

where $W$ is a nonfuzzy number.

This study adopts a "Likert Scale" of fuzzy numbers starting from 1 to 9 to transform the linguistic values into triangular fuzzy numbers, as shown in Table 2.
4.3. Aggregate the Ratings of Suppliers versus the Criteria. Let $x_{i j t}=\left(e_{i j t}, f_{i j t}, g_{i j t}\right), i=1 \sim m, j=1 \sim n, t=1 \sim l$, be the suitability rating assigned to green supplier $A_{i}$, by decision maker $D_{t}$, for criterion $C_{j}$. The averaged suitability rating, $x_{i j}=\left(e_{i j}, f_{i j}, g_{i j}\right)$, can be evaluated as follows:

$$
x_{i j}=\frac{1}{l} \otimes\left(x_{i j 1} \oplus x_{i j 2} \oplus \cdots \oplus x_{i j t} \oplus \cdots \oplus x_{i j l}\right)
$$

where $e_{i j}=(1 / l) \sum_{t=1}^{l} e_{i j t}, f_{i j}=(1 / l) \sum_{t=1}^{l} f_{i j t}$, and $g_{i j}=$ $(1 / l) \sum_{t=1}^{l} g_{i j t}$.

4.4. Normalize Performance of Suppliers versus Criteria. To ensure compatibility between average ratings and average weights, the average ratings are normalized into comparable scales. Suppose that $r_{i j}=\left(a_{i j}, b_{i j}, c_{i j}\right)$ is the performance of green supplier $i$ on criteria $j$. The normalized value $x_{i j}$ can then be denoted as follows:

$$
\begin{aligned}
& x_{i j}=\left(\frac{a_{i j}}{c_{j}^{*}}, \frac{b_{i j}}{c_{j}^{*}}, \frac{c_{i j}}{c_{j}^{*}}\right), \quad j \in B, \\
& x_{i j}=\left(\frac{a_{j}^{-}}{c_{i j}}, \frac{a_{j}^{-}}{b_{i j}}, \frac{a_{j}^{-}}{a_{i j}}\right), \quad j \in C,
\end{aligned}
$$

where $a_{j}^{-}=\min _{i} a_{i j}, c_{j}^{*}=\max _{i} c_{i j}, i=1, \ldots, m$, and $j=$ $1, \ldots, n$.

4.5. Calculate Normalized Weighted Rating. The normalized weighted ratings $G_{i}$ are calculated by multiplying the normalized average rating $x_{i j}$ with its associated weights $w_{j t}$ as follows:

$$
G_{i}=x_{i j} \otimes w_{j}, \quad i=1, \ldots, m, \quad j=1, \ldots, h .
$$

4.6. Calculate $A^{+}, A^{-}, d_{i}^{+}$, and $d_{i}^{-}$. The fuzzy positiveideal solution (FPIS, $A^{+}$) and fuzzy negative-ideal solution (FNIS, $A^{-}$) are obtained as follows:

$$
\begin{aligned}
& A^{+}=(1.0,1.0,1.0), \\
& A^{-}=(0.0,0.0,0.0) .
\end{aligned}
$$

The distance of each green supplier $A_{i}, i=1, \ldots, m$, from $A^{+}$ and $A^{-}$is calculated as follows:

$$
\begin{aligned}
& d_{i}^{+}=\sqrt{\sum_{i=1}^{n}\left(G_{i}-A^{+}\right)^{2}} \\
& d_{i}^{-}=\sqrt{\sum_{i=1}^{n}\left(G_{i}-A^{-}\right)^{2}}
\end{aligned}
$$

where $d_{i}^{+}$represents the shortest distance of alternative $A_{i}$ and $d_{i}^{-}$represents the farthest distance of green supplier $A_{i}$. 
TABLE 2: Linguistic variables describing weights of the "HOWs" criteria.

\begin{tabular}{lc}
\hline Linguistic scale for importance & Triangular fuzzy scale $M=(l, m, u)$ \\
\hline Just equal & $(1.0,1.0,1.0)$ \\
Equal importance & $(1.0,1.0,3.0)$ \\
Weak importance & $(1.0,3.0,5.0)$ \\
Strong importance & $(3.0,5.0,7.0)$ \\
Very strong importance & $(5.0,7.0,9.0)$ \\
Extremely importance & $(7.0,9.0,9.0)$ \\
If factor $i$ has one of the above numbers assigned to it when compared to & Reciprocals of above \\
factor $j$, then $j$ has the reciprocal value when compared with $i$ & $M_{1}^{-1} \approx\left(1 / u_{1}, 1 / m_{1}, 1 / l_{1}\right)$ \\
\hline
\end{tabular}

4.7. Obtain the Closeness Coefficient. The closeness coefficient of each green supplier, which is usually defined to determine the ranking order of all green suppliers, is calculated as follows:

$$
\mathrm{CC}_{i}=\frac{d_{i}^{-}}{d_{i}^{+}+d_{i}^{-}}
$$

A higher value of the closeness coefficient indicates that an alternative is simultaneously closer to PIS and further from NIS. The closeness coefficient of each alternative is used to determine the ranking order of all green suppliers and indicates the best one among a set of given feasible green suppliers.

\section{Case Study}

In this paper, a comprehensive green supplier selection model is proposed by considering the important criteria in economic and environmental aspects for evaluating green suppliers. The proposed method is applied on the case of the Taiwanese optical prism (TOP) manufacturing entity in Luminance Enhancement Film (LEF) industry to solve green suppliers selection.

TOP, founded in late 2003, is the leading optical prism manufacturer in Taiwan. TOP focuses on advanced product development and quality improvement. However, TOP is now dealing with the increase in competition. Moreover, the LCD product life cycle is very short; qualified suppliers as TOP frequently have to provide innovative products within a limited lead time for customers verification to meet timeto-market as well. Consequently, with the purpose of maintaining the existing customers satisfaction and attracting new international customers to improve market share, the selection of quality constant green suppliers for long term cooperation is extremely essential for survival of TOP.

When TOP confirmed its role and strategy as a green supplier, TOP needs to evaluate its core competences and identify the gap between customer needs and consultant suggestions. TOP then restructures the ecological environment of the industry. TOP has employed the green SCM simultaneously considering environmental and economic aspects to either comply with regulation or meet customer needs. Furthermore, TOP has proactively invested both quality and environmental management system, such as quality system of economic criteria ISO9001 and QC080000 and environmental criteria ISO14001 and OHSAS18001. TOP has implemented a continuous quality improvement program and constituted an international standard as a platform to training staffs as well as suppliers. Those activities either save the costs of customers involved with their supplier development program or strengthen TOP's green brand image.

TOP has learned and accumulated plenty of green SCM domain knowledge and capabilities as a main supplier of LCD supply chain through the two-stage process of the raw material quality verification and integration all of material in one product for each customer. Thus, TOP reversely requests the suppliers to comply with its customer environmental and economic requirement. Under the consensus of a multidisciplinary group of decision makers with various points of view and representing the different services of the company, TOP's managers and heads of departments have decided that product price, ISO quality system, and lead time are economic criteria. Green technology and environmental certificate are environmental criteria. The managers of the departments such as Employee Health and Safety, Production, Quality Control and Assessment, and Purchasing were required to make their evaluation, respectively.

In reality, TOP must work with suppliers for green product development. Quality control and supply ability of economic criteria are the most important customer requirement factors which related to green products. TOP's management team continuously integrates resources to investigate green products, such as light, lean production, and energy saving, to satisfy stakeholders. TOP is keeping good relationship with the suppliers that will benefit from the purchasing materials if needed. Additionally, TOP also maintains good relationship with customers who will provide TOP opportunities in innovative product developing and meeting the needs of customers easier.

The case revealed that the green criteria such as environment and sustainability do not yet play a crucial role within green supplier selection procedures in enterprise practice. Due to the environmental regulations, suppliers must meet some minimum requirements in order to be eligible to work with focal firms on the supply chain. After that, most of the companies do not apply environmental criteria to discriminate qualified suppliers; instead customers require suppliers to provide information such as Certificate of Nonuse of 
TABLE 3: Fuzzy pairwise comparison of economic and environmental criteria.

\begin{tabular}{lccccc}
\hline Criteria & $C_{1}$ & $C_{2}$ & $C_{3}$ & $C_{4}$ & $C_{5}$ \\
\hline$C_{1}$ & $(1.0,1.0,1.0)$ & $(1.0,3.0,5.0)$ & $(5.0,7.0,9.0)$ & $(1.0,3.0,5.0)$ & $(1.0,1.0,3.0)$ \\
$C_{2}$ & $(1 / 5,1 / 3,1 / 1)$ & $(1.0,1.0,1.0)$ & $(1 / 9,1 / 7,1 / 5)$ & $(1 / 5,1 / 3,1 / 1)$ & $(5.0,7.0,9.0)$ \\
$C_{3}$ & $(1 / 9,1 / 7,1 / 5)$ & $(5.0,7.0,9.0)$ & $(1.0,1.0,1.0)$ & $(1 / 7,1 / 5,1 / 3)$ & $(1 / 7,1 / 5,1 / 3)$ \\
$C_{4}$ & $(1 / 5,1 / 3,1 / 1)$ & $(1.0,3.0,5.0)$ & $(3.0,5.0,7.0)$ & $(1.0,1.0,1.0)$ & $(1 / 3,1 / 1,1 / 1)$ \\
$C_{5}$ & $(1 / 3,1 / 1,1 / 1)$ & $(1 / 9,1 / 7,1 / 5)$ & $(3.0,5.0,7.0)$ & $(1.0,1.0,3.0)$ & $(1.0,1.0,1.0)$ \\
\hline
\end{tabular}

TABLE 4: Fuzzy weights of the economic and environmental criteria.

\begin{tabular}{lc}
\hline Criteria & Fuzzy weight \\
\hline$C_{1}$ & $(0.123 ; 0.295 ; 0.699)$ \\
$C_{2}$ & $(0.089 ; 0.173 ; 0.371)$ \\
$C_{3}$ & $(0.087 ; 0.168 ; 0.330)$ \\
$C_{4}$ & $(0.076 ; 0.203 ; 0.456)$ \\
$C_{5}$ & $(0.074 ; 0.160 ; 0.371)$ \\
\hline
\end{tabular}

Controlled Substances, Certificate of Nonuse of Other Controlled Substances, Material Safety Data Sheet, and Test Report of customer assigned items issued by SGS annually. Those certificates concern quality of economic criterion and pollution control of environmental criterion.

According to institutional theory, implementation of green SCM is due to mimetic and normative (competitive and bench marking) mechanisms. Facing environmental protection pressure and legitimacy isomorphism pressure, enterprises must comply with social expectation and maintain consistency with external environment to survive. Thus, the environmental and economic dimensions must be considered simultaneously [5]. Consequently, the proposed method is applied on the case of TOP following the steps below.

Step 1 (identify a number of economic and environmental criteria). In this study, the data used as input to implement the proposed green supplier selection and evaluate the method were collected by means of semistructured interviews with the top managers and head of departments. Four company managers were required to make their evaluation, respectively, according to their preferences for important weights of selection criteria and ratings of green suppliers.

Using Table 1 and discussions with a company's top managers and heads of departments, five criteria of economics and environment for green supplier selection were selected. Economic criteria include product price $\left(C_{1}\right)$, ISO quality system $\left(C_{2}\right)$, and lead time $\left(C_{3}\right)$. Green technology $\left(C_{4}\right)$ and environmental certificate $\left(C_{5}\right)$ are environmental criteria.

Step 2 (aggregate the important weights of the criteria). After the determination of the green supplier criteria, each of four company managers is asked to conduct a pairwise comparison with regard to the different criteria using the fuzzy linguistic assessment variables (see Table 2 for these variables). The completed matrices for the required cell are shown in Table 3. Applying (5)-(8), the final weights of the economic and environmental criteria are obtained as shown in Table 4.
Step 3 (aggregate the ratings of suppliers versus the criteria). After the determination of the suppliers assessment criteria, four company managers rate each supplier according to each criterion. A linguistic rating set of $S$ was used to express the opinions of the managers, where $S=(V P, P, F, G, V G), V P$ $($ Very Poor $)=(0.0,0.1,0.2), \mathrm{P}($ Poor $)=(0.1,0.3,0.5), \mathrm{F}($ Fair $)=$ $(0.3,0.5,0.7), \mathrm{G}($ Good $)=(0.5,0.7,0.9)$, and VG $($ Very Good $)$ $=(0.8,0.9,1.0)$. Table 5 gives the aggregated suitability ratings of four green suppliers $\left(A_{1}, A_{2}, A_{3}\right.$, and $\left.A_{4}\right)$ using (12).

Step 4 (normalized performance of suppliers versus criteria). For simplicity and practicality, all of the fuzzy numbers in this paper are defined in the closed interval $[0,1]$. Consequently, the normalization procedure is no longer needed.

Step 5 (calculate normalized weighted rating). Using (14), the normalized weighted ratings $G_{i}$ can be obtained as shown in Table 6 .

Step 6 (calculate $A^{+}, A^{-}, d_{i}^{+}$, and $d_{i}^{-}$). As shown in Table 7, the distance of each green supplier from $A^{+}$and $A^{-}$can be calculated by (15) (16).

Step 7 (obtain the closeness coefficient). The closeness coefficients of green suppliers can be calculated by (17), as shown in Table 8. Therefore, the ranking order of the four green suppliers is $A_{3}>A_{4}>A_{1}>A_{2}$. Consequently, the best green supplier is $A_{3}$.

\section{Conclusion}

While the types of industry vary, the key strategies of green supplier selection also are changed. Nevertheless, all industries should concern suppliers from both economic and environmental aspects, because suppliers could influence firms' performance and stakeholders.

Green supplier selection is an important and complicated MCDM problem, requiring evaluation of multiple economic and environmental criteria incorporating vagueness and imprecision with the involvement of a group of experts. Although numerous studies have used economic criteria in the supplier selection process, limited studies have considered the economic and environmental criteria simultaneously. The implementation of green supply management was not well understood. This paper has proposed an integrated fuzzy MCDM approach to support the green suppliers selection and the evaluation process. In the proposed approach, both economic and environmental criteria were considered. In order to overcome the shortcomings of the existing fuzzy 
TABLE 5: Aggregate of the green supplier ratings versus criteria.

\begin{tabular}{|c|c|c|c|c|c|c|}
\hline \multirow{2}{*}{ Criteria } & \multirow{2}{*}{ Green suppliers } & \multicolumn{4}{|c|}{ Company managers } & \multirow{2}{*}{$r_{i j}$} \\
\hline & & $D_{1}$ & $\mathrm{D}_{2}$ & $D_{3}$ & $D_{4}$ & \\
\hline \multirow{4}{*}{$C_{1}$} & $A_{1}$ & VG & G & G & VG & $(0.650,0.800,0.950)$ \\
\hline & $A_{2}$ & $\mathrm{~F}$ & G & G & $\mathrm{F}$ & $(0.400,0.600,0.800)$ \\
\hline & $A_{3}$ & G & G & G & G & $(0.500,0.700,0.900)$ \\
\hline & $A_{4}$ & G & $\mathrm{F}$ & G & G & $(0.450,0.650,0.850)$ \\
\hline \multirow{4}{*}{$C_{2}$} & $A_{1}$ & G & G & G & G & $(0.500,0.700,0.900)$ \\
\hline & $A_{2}$ & $\mathrm{~F}$ & $\mathrm{~F}$ & G & $\mathrm{F}$ & $(0.350,0.550,0.750)$ \\
\hline & $A_{3}$ & G & G & VG & G & $(0.575,0.750,0.925)$ \\
\hline & $A_{4}$ & VG & G & VG & G & $(0.650,0.800,0.950)$ \\
\hline \multirow{4}{*}{$C_{3}$} & $A_{1}$ & G & $\mathrm{F}$ & G & $\mathrm{F}$ & $(0.400,0.600,0.800)$ \\
\hline & $A_{2}$ & $\mathrm{~F}$ & $\mathrm{~F}$ & $\mathrm{~F}$ & G & $(0.350,0.550,0.750)$ \\
\hline & $A_{3}$ & VG & G & VG & G & $(0.650,0.800,0.950)$ \\
\hline & $A_{4}$ & $\mathrm{~F}$ & G & $\mathrm{F}$ & $\mathrm{F}$ & $(0.350,0.550,0.750)$ \\
\hline \multirow{4}{*}{$C_{4}$} & $A_{1}$ & $\mathrm{~F}$ & G & G & $\mathrm{F}$ & $(0.400,0.600,0.800)$ \\
\hline & $A_{2}$ & G & VG & G & G & $(0.575,0.750,0.925)$ \\
\hline & $A_{3}$ & G & VG & VG & G & $(0.650,0.800,0.950)$ \\
\hline & $A_{4}$ & VG & G & VG & G & $(0.650,0.800,0.950)$ \\
\hline \multirow{4}{*}{$C_{5}$} & $A_{1}$ & G & G & G & G & $(0.500,0.700,0.900)$ \\
\hline & $A_{2}$ & VG & G & G & VG & $(0.650,0.800,0.950)$ \\
\hline & $A_{3}$ & G & G & G & VG & $(0.575,0.750,0.925)$ \\
\hline & $A_{4}$ & VG & G & G & VG & $(0.650,0.800,0.950)$ \\
\hline
\end{tabular}

TABLE 6: Normalized weighted ratings of each market segment.

\begin{tabular}{lc}
\hline Green suppliers & $G_{i}$ \\
\hline$A_{1}$ & $(0.045,0.138,0.392)$ \\
$A_{2}$ & $(0.041,0.129,0.372)$ \\
$A_{3}$ & $(0.052,0.151,0.413)$ \\
$A_{4}$ & $(0.048,0.143,0.396)$ \\
\hline
\end{tabular}

TABLE 7: The distance of each green supplier from $A^{+}$and $A^{-}$.

\begin{tabular}{lcc}
\hline Green suppliers & $d^{+}$ & $d^{-}$ \\
\hline$A_{1}$ & 1.422 & 0.418 \\
$A_{2}$ & 1.440 & 0.396 \\
$A_{3}$ & 1.402 & 0.442 \\
$A_{4}$ & 1.416 & 0.424 \\
\hline
\end{tabular}

TABLE 8: Closeness coefficients of alternatives.

\begin{tabular}{lcc}
\hline Alternatives & Closeness coefficient & Ranking \\
\hline$A_{1}$ & 0.227 & 3 \\
$A_{2}$ & 0.216 & 4 \\
$A_{3}$ & 0.240 & 1 \\
$A_{4}$ & 0.230 & 2 \\
\hline
\end{tabular}

TOPSIS technique, this study has integrated the fuzzy TOPSIS technique with the fuzzy AHP method, to determine the important weights of economic and environmental criteria. Finally, the proposed approach was employed to solve a real problem in the LEF industry. The results showed that the proposed approach is effective in supplier selection for the company. The application also indicated that the computational procedure is efficient and easy to use in practice. Future research should focus on developing an extension of fuzzy MCDM approach to segment the green suppliers based on the economic and environmental aspects. Different methods may be applied to select green suppliers and the results should be compared with the proposed approach. The proposed approach can also be applied to other management problems with similar settings.

\section{Conflict of Interests}

The authors declare that there is no conflict of interests regarding the publication of this paper.

\section{References}

[1] Y.-S. Chen and C.-H. Chang, "The determinants of green product development performance: Green dynamic capabilities, green transformational leadership, and green creativity," Journal of Business Ethics, vol. 116, no. 1, pp. 107-119, 2013.

[2] A. H. I. Lee, H.-Y. Kang, C.-F. Hsu, and H.-C. Hung, "A green supplier selection model for high-tech industry," Expert Systems with Applications, vol. 36, no. 4, pp. 7917-7927, 2009.

[3] K. Govindan, S. Rajendran, J. Sarkis, and P. Murugesan, "Multi criteria decision making approaches for green supplier evaluation and selection: a literature review," Journal of Cleaner Production, vol. 98, pp. 66-83, 2015. 
[4] R. J. Kuo, Y. C. Wang, and F. C. Tien, "Integration of artificial neural network and MADA methods for green supplier selection," Journal of Cleaner Production, vol. 18, no. 12, pp. 1161-1170, 2010.

[5] A. Gunasekaran and D. Gallear, "Special Issue on Sustainable development of manufacturing and services," International Journal of Production Economics, vol. 140, no. 1, pp. 1-6, 2012.

[6] J. Sarkis, Q. Zhu, and K.-H. Lai, "An organizational theoretic review of green supply chain management literature," International Journal of Production Economics, vol. 130, no. 1, pp. 1-15, 2011.

[7] A. Appolloni, H. Sun, F. Jia, and X. Li, "Green Procurement in the private sector: a state of the art review between 1996 and 2013," Journal of Cleaner Production, vol. 85, pp. 122-133, 2014.

[8] H. C. Pimenta and P. D. Ball, "Analysis of environmental sustainability practices across upstream supply chain management," Procedia CIRP, vol. 26, pp. 677-682, 2015.

[9] C.-L. Hwang and K. Yoon, Multiple Attribute Decision MakingMethods and Applications: A State of the Art Survey, Springer, New York, NY, USA, 1981.

[10] H.-S. Shih, H.-J. Shyur, and E. S. Lee, "An extension of TOPSIS for group decision making," Mathematical and Computer Modelling, vol. 45, no. 7-8, pp. 801-813, 2007.

[11] T. L. Saaty, The Analytical Hierarchy Process, McGraw-Hill, New York, NY, USA, 1980.

[12] G. Büyüközkan and G. Çifçi, "Evaluation of the green supply chain management practices: a fuzzy ANP approach," Production Planning and Control, vol. 23, no. 6, pp. 405-418, 2012.

[13] C.-C. Sun, "A performance evaluation model by integrating fuzzy AHP and fuzzy TOPSIS methods," Expert Systems with Applications, vol. 37, no. 12, pp. 7745-7754, 2010.

[14] W. Xia and Z. Wu, "Supplier selection with multiple criteria in volume discount environments," Omega, vol. 35, no. 5, pp. 494504, 2007.

[15] I. Chamodrakas, D. Batis, and D. Martakos, "Supplier selection in electronic marketplaces using satisficing and fuzzy AHP," Expert Systems with Applications, vol. 37, no. 1, pp. 490-498, 2010.

[16] K. Shaw, R. Shankar, S. S. Yadav, and L. S. Thakur, "Supplier selection using fuzzy AHP and fuzzy multi-objective linear programming for developing low carbon supply chain," Expert Systems with Applications, vol. 39, no. 9, pp. 8182-8192, 2012.

[17] O. Kilincci and S. A. Onal, "Fuzzy AHP approach for supplier selection in a washing machine company," Expert Systems with Applications, vol. 38, no. 8, pp. 9656-9664, 2011.

[18] A. H. I. Lee, "A fuzzy supplier selection model with the consideration of benefits, opportunities, costs and risks," Expert Systems with Applications, vol. 36, no. 2, pp. 2879-2893, 2009.

[19] C. Bai and J. Sarkis, "Green supplier development: analytical evaluation using rough set theory," Journal of Cleaner Production, vol. 18, no. 12, pp. 1200-1210, 2010.

[20] M. Abdollahi, M. Arvan, and J. Razmi, "An integrated approach for supplier portfolio selection: lean or agile?" Expert Systems with Applications, vol. 42, no. 1, pp. 679-690, 2015.

[21] M. S. Memon, Y. H. Lee, and S. I. Mari, "Group multi-criteria supplier selection using combined grey systems theory and uncertainty theory," Expert Systems with Applications, vol. 42, no. 21, pp. 7951-7959, 2015.

[22] S. H. Hashemi, A. Karimi, and M. Tavana, "An integrated green supplier selection approach with analytic network process and improved Grey relational analysis," International Journal of Production Economics, vol. 159, pp. 178-191, 2015.
[23] M. Punniyamoorthy, P. Mathiyalagan, and P. Parthiban, "A strategic model using structural equation modeling and fuzzy logic in supplier selection," Expert Systems with Applications, vol. 38, no. 1, pp. 458-474, 2011.

[24] R. M. Grisi, L. Guerra, and G. Naviglio, "Supplier performance evaluation for green supply chain management," in Business Performance Measurement and Management, pp. 149-163, Springer, Berlin, Germany, 2010.

[25] F. Mafakheri, M. Breton, and A. Ghoniem, "Supplier selectionorder allocation: a two-stage multiple criteria dynamic programming approach," International Journal of Production Economics, vol. 132, no. 1, pp. 52-57, 2011.

[26] Y.-J. Chen, "Structured methodology for supplier selection and evaluation in a supply chain," Information Sciences, vol. 181, no. 9, pp. 1651-1670, 2011.

[27] W.-P. Wang, "A fuzzy linguistic computing approach to supplier evaluation," Applied Mathematical Modelling, vol. 34, no. 10, pp. 3130-3141, 2010.

[28] M.-L. Tseng and A. S. F. Chiu, "Evaluating firm's green supply chain management in linguistic preferences," Journal of Cleaner Production, vol. 40, pp. 22-31, 2013.

[29] Q. Zhu, Y. Dou, and J. Sarkis, "A portfolio-based analysis for green supplier management using the analytical network process," Supply Chain Management, vol. 15, no. 4, pp. 306-319, 2010.

[30] G. A. Keskin, S. Ilhan, and C. Özkan, "The Fuzzy ART algorithm: a categorization method for supplier evaluation and selection," Expert Systems with Applications, vol. 37, no. 2, pp. 1235-1240, 2010.

[31] C.-Y. Shen and K.-T. Yu, "Enhancing the efficacy of supplier selection decision-making on the initial stage of new product development: a hybrid fuzzy approach considering the strategic and operational factors simultaneously," Expert Systems with Applications, vol. 36, no. 8, pp. 11271-11281, 2009.

[32] K. Govindan, R. Khodaverdi, and A. Jafarian, "A fuzzy multi criteria approach for measuring sustainability performance of a supplier based on triple bottom line approach," Journal of Cleaner Production, vol. 47, pp. 345-354, 2013.

[33] G. Tuzkaya, A. Ozgen, D. Ozgen, and U. R. Tuzkaya, "Environmental performance evaluation of suppliers: a hybrid fuzzy multi-criteria decision approach," International Journal of Environmental Science \& Technology, vol. 6, no. 3, pp. 477-490, 2009.

[34] Q. Zhu, J. Sarkis, and K.-H. Lai, "Initiatives and outcomes of green supply chain management implementation by Chinese manufacturers," Journal of Environmental Management, vol. 85, no. 1, pp. 179-189, 2007.

[35] W.-C. Yeh and M.-C. Chuang, "Using multi-objective genetic algorithm for partner selection in green supply chain problems," Expert Systems with Applications, vol. 38, no. 4, pp. 4244-4253, 2011.

[36] A. Awasthi, S. S. Chauhan, and S. K. Goyal, "A fuzzy multicriteria approach for evaluating environmental performance of suppliers," International Journal of Production Economics, vol. 126, no. 2, pp. 370-378, 2010.

[37] J. Sarkis, "Manufacturing's role in corporate environmental sustainability-Concerns for the new millennium," International Journal of Operations \& Production Management, vol. 21, no. 56, pp. 666-686, 2001.

[38] S. M. Mirhedayatian, M. Azadi, and R. Farzipoor Saen, "A novel network data envelopment analysis model for evaluating green supply chain management," International Journal of Production Economics, vol. 147, pp. 544-554, 2014. 
[39] C. Wu and D. Barnes, "An integrated model for green partner selection and supply chain construction," Journal of Cleaner Production, vol. 112, pp. 2114-2132, 2016.

[40] G. Bruno, E. Esposito, A. Genovese, and R. Passaro, "AHP-based approaches for supplier evaluation: problems and perspectives," Journal of Purchasing and Supply Management, vol. 18, no. 3, pp. 159-172, 2012.

[41] F. R. L. Junior, L. Osiro, and L. C. R. Carpinetti, "A comparison between Fuzzy AHP and Fuzzy TOPSIS methods to supplier selection," Applied Soft Computing, vol. 21, pp. 194-209, 2014.

[42] A. Kawa and W. W. Koczkodaj, "Supplier evaluation process by pairwise comparisons," Mathematical Problems in Engineering, vol. 2015, Article ID 976742, 9 pages, 2015.

[43] X. Deng, Y. Hu, Y. Deng, and S. Mahadevan, "Supplier selection using AHP methodology extended by D numbers," Expert Systems with Applications, vol. 41, no. 1, pp. 156-167, 2014.

[44] N. Xie and J. Xin, "Interval grey numbers based multi-attribute decision making method for supplier selection," Kybernetes, vol. 43, no. 7, pp. 1064-1078, 2014.

[45] J. Lee, H. Cho, and Y. S. Kim, "Assessing business impacts of agility criterion and order allocation strategy in multi-criteria supplier selection," Expert Systems with Applications, vol. 42, no. 3, pp. 1136-1148, 2015.

[46] L. Shen, L. Olfat, K. Govindan, R. Khodaverdi, and A. Diabat, "A fuzzy multi criteria approach for evaluating green supplier's performance in green supply chain with linguistic preferences," Resources, Conservation and Recycling, vol. 74, pp. 170-179, 2012.

[47] B. Kanga, Y. Hu, Y. Deng, and D. Zhou, "A new methodology of multicriteria decision-making in supplier selection based on Z-numbers," Mathematical Problems in Engineering, vol. 2016, Article ID 8475987, 17 pages, 2016.

[48] N. Asthana and M. Gupta, "Supplier selection using artificial neural network and genetic algorithm," International Journal of Indian Culture and Business Management, vol. 11, no. 4, pp. 457472, 2015.

[49] D. Dubois and H. Prade, "Operations on fuzzy numbers," International Journal of Systems Science, vol. 9, no. 6, pp. 613-626, 1978.

[50] A. Kaufmann and M. M. Gupta, Introduction to Fuzzy Arithmetic: Theory and Applications, The Arden Shakespeare, 1991.

[51] L. A. Zadeh, "The concept of a linguistic variable and its application to approximate reasoning-I," Information Sciences, vol. 8, no. 3, pp. 199-249, 1975.

[52] L. A. Zadeh, "The concept of a linguistic variable and its application to approximate reasoning-II," Information Sciences, vol. 8, no. 4, pp. 301-357, 1975.

[53] D.-Y. Chang, "Applications of the extent analysis method on fuzzy AHP," European Journal of Operational Research, vol. 95, no. 3, pp. 649-655, 1996. 


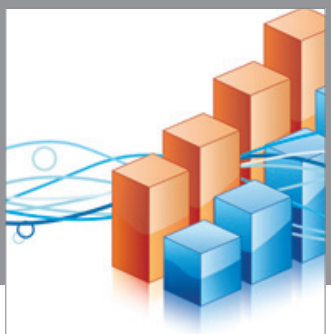

Advances in

Operations Research

vatem alat4

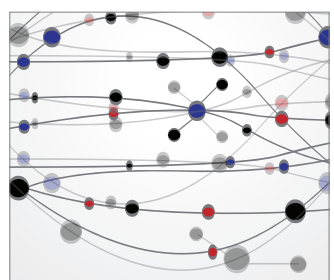

\section{The Scientific} World Journal

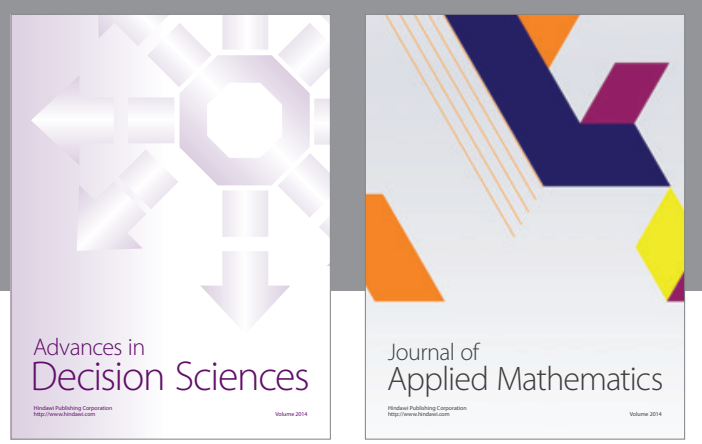

Algebra

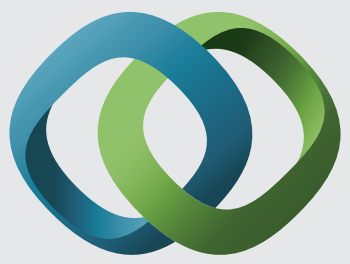

\section{Hindawi}

Submit your manuscripts at

http://www.hindawi.com
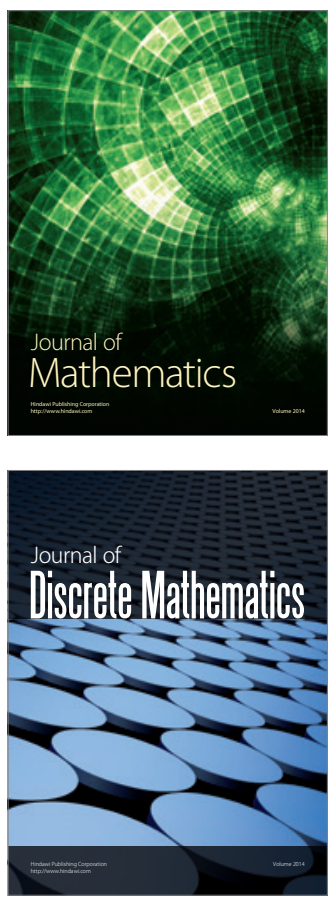

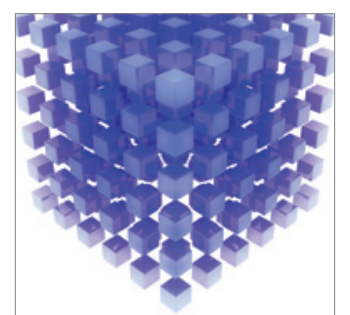

Mathematical Problems in Engineering
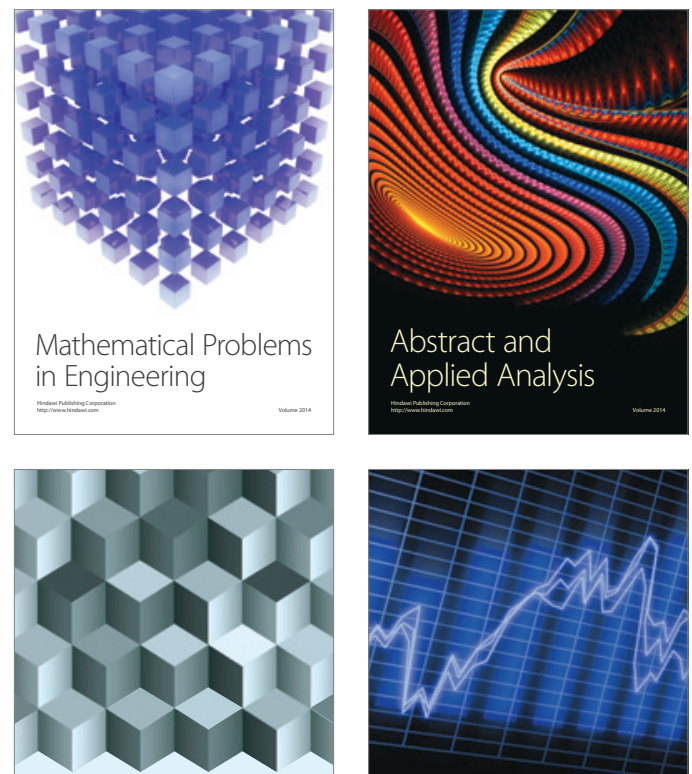

Journal of

Function Spaces

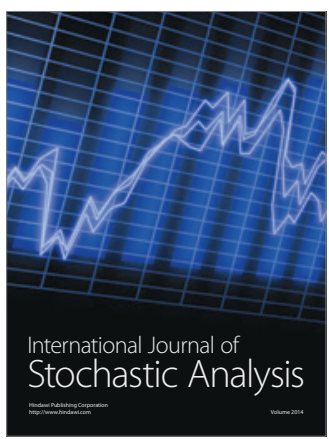

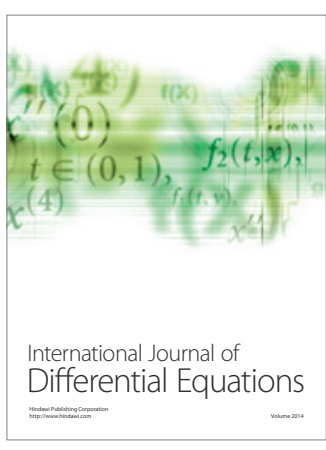
